\title{
Relationship of Mandibular Ramus Dimensions to Lower Third Molar Impaction
}

\author{
Talat Hasan Al-Gunaid ${ }^{1,2} \quad$ Abdul Kadir Bukhari ${ }^{3} \quad$ Sara M. El Khateeb ${ }^{4,5} \quad$ Masaki Yamaki $^{6}$
}

${ }^{1}$ Department of Pediatric Dentistry and Orthodontics, College of Dentistry, Taibah University, KSA

2Department of Orthodontics and Pediatric Dentistry, Faculty of Dentistry, Ibb University, Yemen

${ }^{3}$ Department of Pediatric Dentistry and Orthodontics, College of Dentistry, Taibah University, KSA

${ }^{4}$ Department of Basic Dental Sciences, College of Dentistry, Princess Nourah Bint Abdulrahman University, KSA

${ }^{5}$ Department of Oral Medicine, Periodontology, Diagnosis and Radiology, Faculty of Dentistry, Ain Shams University, Cairo, Egypt

${ }^{6}$ Department of Oral Life Science, Division of Orthodontics, Graduate School of Medical and Dental Sciences, Niigata

University, Japan

\begin{abstract}
Address for correspondence Talat Hasan Al-Gunaid, DDS, PhD, Associate Professor and Coordinator, Department of Pediatric Dentistry and Orthodontics, College of Dentistry, Taibah University, KSA (e-mail: gunaid2000@hotmail.com).
\end{abstract}

Eur J Dent 2019;13:213-221

\begin{abstract}
Objectives The aim of this study was to investigate the mandibular ramus features that could contribute to the etiology of mandibular third molar impaction.

Materials and Methods Two hundred and forty subjects were divided into two groups: impacted group: 115 subjects presented with an impacted mandibular third molar, and control group: 125 subjects with the normal mandibular third molar eruption. Digital panoramic radiographs were used, and four angular and twelve linear measurements were done. Comparisons between groups were done using Student's $t$-test. Pearson correlation and linear regression tests were used to assess the degree of relationship between retromolar space and mandibular measurements.

Results Control group showed significant greater measurements in most of the variables, whereas the impacted group showed significant larger gonial angle and larger inclination of lower posterior teeth than the control group. Significant correlations were found between retromolar space and coronoid height, ramal heights, ramus notch depths, the inclination of lower posterior teeth, and retromolar space/3M width

Keywords

- ramal dimensions

- lower third molar

- impaction ratio in both groups.

Conclusion The present study found that the configuration of the mandibular ramus appears to be discrete in many aspects in the erupted other than impacted lower third molars subjects, which might be a possible cause for the impaction.
\end{abstract}

\section{Introduction}

Third molars are the most frequently impacted tooth in the dental arch. ${ }^{1}$ The influence of the third molars on the anterior teeth crowding and its stability after orthodontic treatment is controversial. However, no evidence to support or deny the fact that these teeth are the only or even the primary etiological factor in the post-treatment incisor crowding. ${ }^{2}$
The etiology of third molar impaction is unclear. However, it has been reported that it might be linked with the short distance from the distal surface of the second molar to the ramus, ${ }^{3-6}$ the mandibular growth amount and direction, ${ }^{3,7-9}$ the width and remodeling of the ramus, degree of the third molar maturation, and might be due to the inclination of posterior teeth and discrepancy between the dentition and the jaws. $^{3}$ 
Panoramic radiographs are widely used in the profession of dentistry ${ }^{10,11}$ as it gives quick, low-cost, small radiation dosages and provides a bilateral view of the mandible compared with other sophisticated diagnostic tools. It is also considered as one of the proper radiographic techniques that used to assess lower third molar space and mandibular linear and angular dimensions. The drawbacks include distortion and magnification errors. ${ }^{12}$ Ongkosuwito et $\mathrm{al}^{13}$ compared orthopantomogram (OPG) with lateral cephalogram using three mandibular length measurements. They concluded that measurements of mandibular lengths such as condylion (Co)-gonion (Go), gonion-menton, and condylion-menton on the lateral cephalogram are as useful as on an OPG. They insisted on that the choice of whether to use panoramic radiograph or lateral cephalogram depends on the clinician's personal experience and that both methods can be equally well applied.

Our hypothesis suggests no association between the lower third molar impaction and mandibular ramus measurements. Therefore, the aim of this study was directed to investigate the mandibular ramus features that could contribute to the etiology of mandibular third molar impaction and compare them with a control group of normal erupted lower third molars.

\section{Materials and Methods}

The current study had been approved by the Research Ethics Committee, College of Dentistry, Taibah University. The material of this study comprised the records of 2,981 consecutive patients seeking dental treatment at the Faculty of Dentistry, Taibah University. The OPGs are routinely taken for all patients attending our college hospital and used for screening and pretreatment evaluation.

Out of 2,981 panoramic radiographs, only 240 OPG of male and female patients and their related data were selected from these records. The inclusion criteria were: all patients were 21 years old or older, good quality of OPG, complete normal mandibular dentition, complete root formation of lower third molars, no history of orthodontic treatment, and nonsyndromic patients.

The sample was divided into two groups according to the status of the mandibular third molars:

- Impacted group: It comprised of 115 subjects (68 males and 47 females). A mandibular third molar was considered impacted if it is either partially erupted or impacted and was not in functional occlusion.

- Control group: It comprised of 125 subjects (89 males and 36 females) with the normal mandibular third molar eruption.

The mean age of the total sample was $27.2 \pm 6.7$ years (range: 21-54 years). The mean age of the impacted mandibular third molar group was $23.5 \pm 3.2$ years and $30.5 \pm$ 6.9 years for the control group. Digital panoramic radiographs were taken using the panoramic-cephalometric machine (Kodak 8000 C Digital Panoramic and Cephalometric, the Netherland). Two experienced technicians took all digital panoramic radiographs according to the standard instructions provided by the manufacturer. The magnification of the device was $\times 1.15$.

The radiographs were then imported to analysis software for tracing and measurements. Nineteen landmarks were defined on the radiographs (-Fig. 1, - Table 1). Four angular and twelve linear measurements were done (-Figs. 2 and 3, - Tables 2 and 3) using Image J 1.48a software (National Institutes of Health, Bethesda, United States). All measurements were done to the nearest two decimal points obtained from the software program.

To evaluate and correct the magnification errors and to set the scale of the software program to a known distance, two stainless steel wires $(0.07 \mathrm{~mm})$ one vertical, parallel to the long axis of the tooth, and one horizontal, parallel to the incisal edge, were bonded to the upper central incisors of the second author. Each length of wire was premeasured using a digital caliper. Additionally, we also measured the mesiodistal width of the second molar from a study model of the same person and then used as a known distance. One investigator did all tracings and measurements.

\section{Methodological Error}

An error analysis of tracing and measurements were performed using 30 radiographs traced twice at the 1-month interval. The method error was calculated using intraclass correlation coefficient.

\section{Statistical Analysis}

The normality test of Shapiro-Wilk was applied to the data. The data were found to be normally distributed. Mean and standard deviation for the two samples and comparisons between control and impacted groups were done using Student's $t$-test. Pearson correlation and linear regression tests were used to assess the degree of relationship between retromolar space and mandibular measurements. All statistical analyses were performed using SPSS 17.0 software (version 17.0, SPSS, Chicago, Illinois, United States). Our level of significance was set at $p<0.05$.

\section{Results}

The method error was minimal, and the results demonstrated that the reliability for all measurements was excellent and was found to be between 0.89 and 0.99 ( - Table 4 ).

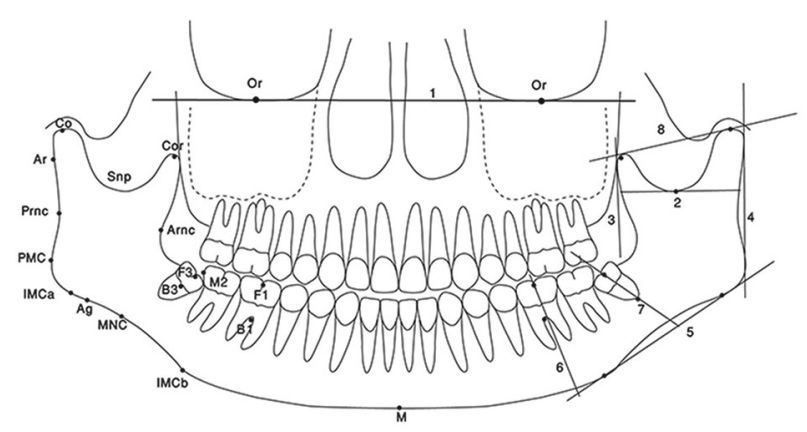

Fig. 1 Landmark and Reference planes 
Table 1 Landmarks and reference planes

\begin{tabular}{|c|c|}
\hline Landmarks & Description \\
\hline Orbitale (Or) & The lowermost point of the bony orbit \\
\hline Condylion (Co) & Most superior point of the head of the mandibular condyle \\
\hline Coronoid point (Cor) & Most superior point of the coronoid process \\
\hline Sigmoid notch point (Snp) & The deepest point of the sigmoid notch of the mandible \\
\hline Articulare (Ar) & $\begin{array}{l}\text { A constructed point at the intersection between the external contour of the cranial } \\
\text { base and the dorsal contour of the condylar head or neck }\end{array}$ \\
\hline PMC & $\begin{array}{l}\text { The point of greatest convexity on the posterior border of the angular process of the } \\
\text { mandible (PMC) }\end{array}$ \\
\hline Posterior ramus notch (Prnc) & The deepest point of the posterior ramus notch concavity \\
\hline Anterior ramus notch (Arnc) & The deepest point of the anterior ramus notch concavity \\
\hline Gonion (Go) & $\begin{array}{l}\text { The constructed point of intersection of the ramus plane and the mandibular } \\
\text { Plane }\end{array}$ \\
\hline IMCa & Posterior point of greatest convexity on the inferior border of the mandible \\
\hline IMCb & Anterior points of greatest convexity on the inferior border of the mandible \\
\hline MNC & The deepest point of the mandibular inferior border notch concavity. \\
\hline Antegonion point $(\mathrm{Ag})$ & $\begin{array}{l}\text { The point in the antegonial notch of the mandible joins the ramus and body of the } \\
\text { mandible }\end{array}$ \\
\hline Mandibular midpoint (M) & $\begin{array}{l}\text { The most inferior midline point on the mandibular symphysis located by projecting } \\
\text { the mental spine on the lower mandibular border }\end{array}$ \\
\hline F1 & The midpoint of the occlusal surface corresponding to fossa of the first molar \\
\hline B1 & The point corresponding to the bifurcation of the first molar \\
\hline F3 & The midpoint of the occlusal surface corresponding to fossa of the third molar \\
\hline B3 & The point corresponding to the bifurcation of the third molar \\
\hline M2 & The distal contact point of lower second molar \\
\hline 1. Orbitale plane & The line connecting the orbitale (Or) points bilaterally \\
\hline 2. Sigmoid notch plane & $\begin{array}{l}\text { A tangential line is drawn from the deepest point on the sigmoid notch (Snp) parallel } \\
\text { to the orbital plane }\end{array}$ \\
\hline 3. Z-plane & $\begin{array}{l}\text { A line tangent to descending anterior border of the ramus of mandible and perpen- } \\
\text { dicular to the sigmoid notch plane }\end{array}$ \\
\hline 4. Ramus plane & $\begin{array}{l}\text { A tangential line of the posterior ramus connecting point Ar with the point of greatest } \\
\text { convexity on the posterior border of the angular process of the mandible (PMC) }\end{array}$ \\
\hline 5. Mandibular plane & $\begin{array}{l}\text { A tangential line of the lower border of the mandibular body [a tangent through the } \\
\text { two points of greatest convexity on the inferior border of the mandible (IMCa and } \\
\text { IMCb)]. }\end{array}$ \\
\hline 6. Long axis of the first molar & $\begin{array}{l}\text { A line is drawn through the midpoint of the occlusal surface and the midpoint of the } \\
\text { bifurcation }\end{array}$ \\
\hline 7. Long axis of the third molar & $\begin{array}{l}\text { A line is drawn through the midpoint of the occlusal surface and the midpoint of the } \\
\text { bifurcation }\end{array}$ \\
\hline 8. Condyle coronoid plane & A-line connecting condylion (Co) and coronoid (Cor) points \\
\hline
\end{tabular}

Table 5 compares the means and standard deviations of the mandibular dimensions between control and impacted groups. Control group showed significant larger measurements in most of the variables presented by longer condylar length $(p<0.001)$, longer coronoid process length $(p<0.05)$, longer ramus height (measured from sigmoid notch point, Snp-antegonion point, $\mathrm{Ag})(p<0.001)$, longer total ramus height (measured from Co-Go) $(p<0.001)$, wider ramal width $(p<0.001)$, deeper sigmoid notch depth $(p<0.001)$, deeper posterior and anterior notch depths $(p<0.001)$, larger retromolar space $(p<0.001)$, higher retromolar area to third molar ratio ( $p<0.001)$, and larger angle of impaction $(p<0.001)$ than impacted group. On the contrary, the impacted group showed only two significant larger measurements than control group presented by a larger gonial angle $(p<0.01)$, and larger inclination of lower posterior teeth $(p<0.05)$ than the control group.

Table 6 shows the correlations coefficient between retromolar space and mandibular dimensions in both control and impacted groups. Significant correlations were found between coronoid height, ramal height, and total ramal height with retromolar space in both groups $(p<0.001)$. 


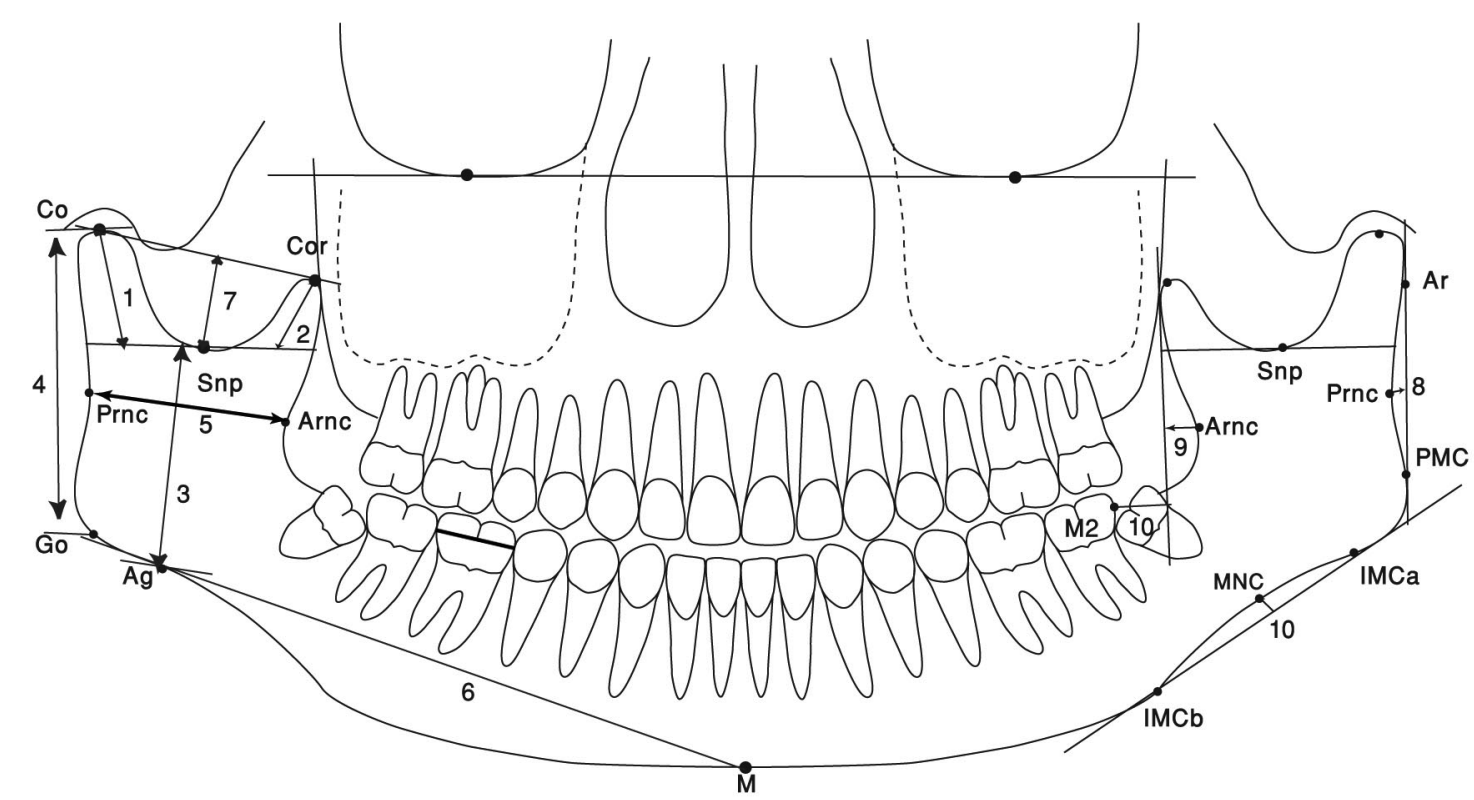

Fig. 2 Linear Measurements

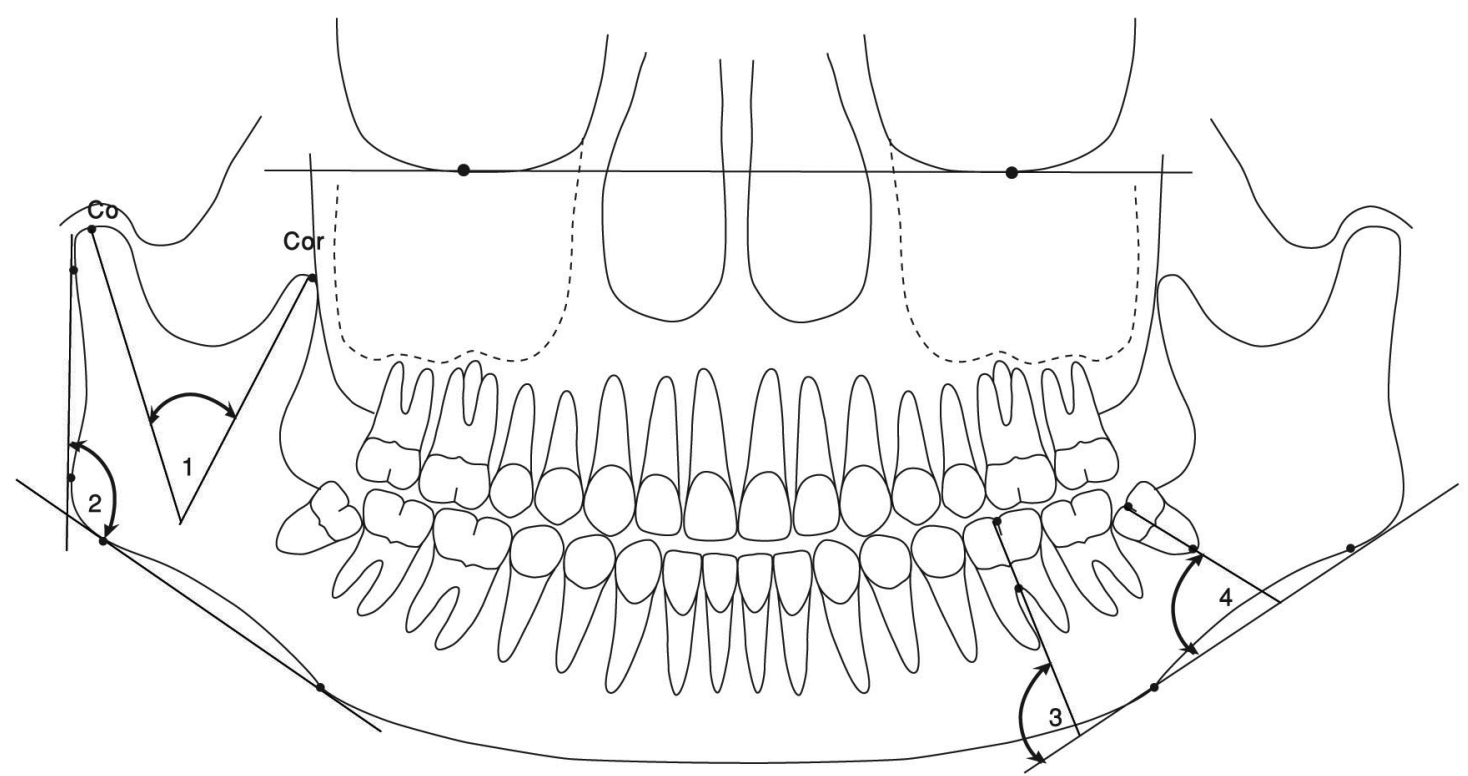

Fig. 3 Angular Measurements

Ramal width showed a significant correlation with retromolar space only in the impacted group $(p<0.05)$. Also, posterior ramus notch depth, anterior ramus notch depth, the inclination of lower posterior teeth, and retromolar space/3M width ratio showed a significant correlation with retromolar space in both groups $(p<0.001)$. Furthermore, gonial angle and angle of impaction showed significant association with retromolar space only in the control group $(p<0.001)$.

\section{Discussion}

The mean age of the total sample was $27.2 \pm 6.7$ years, which is close to the average age reported for the eruption of a mandibular third molar. ${ }^{14-16}$ Scherstén et al ${ }^{17}$ suggested that 20 to 25 years is the most appropriate age for studying the incidence of mandibular third molar impaction. For this reason and in an attempt to minimize the influence of such factors on the measurements, the subjects included in this study were 21 years old or older, as this age essentially completes growth and all third molars have their roots completed by this time.

About the ramal dimensions, condylar length, coronoid length, ramus height, and total ramus height were significantly longer in the normal group than the impacted group. This finding disagrees with the result of Capelli, ${ }^{18}$ who reported that long ascending ramus seems to be indicative of third molar impaction. Also, our result is not in line with that of 
Table 2 Linear measurements

\begin{tabular}{|c|c|c|}
\hline Measurement & Abbreviation & Description \\
\hline 1. Condyle length & Co-Snp (mm) & $\begin{array}{l}\text { Measured from condylion to sigmoid notch plane along the long axis of the } \\
\text { condylar process }\end{array}$ \\
\hline 2. Coronoid length & Cor-Snp (mm) & $\begin{array}{l}\text { Measured from coronoid point to sigmoid notch plane along the long axis of } \\
\text { the coronoid process }\end{array}$ \\
\hline 3. Ramus height & Snp-Ag (mm) & $\begin{array}{l}\text { The distance between sigmoid notch point to antegonion point (excluding } \\
\text { condyle and coronoid) }\end{array}$ \\
\hline 4. Total ramus height & Co-Go (mm) & The distance between condylion to gonion \\
\hline 5. Ramus width & $\begin{array}{l}\text { Prnc-Arnc } \\
(\mathrm{mm})\end{array}$ & The distance from anterior to posterior ramal walls at the level of the midpoint \\
\hline $\begin{array}{l}\text { 6. Mandibular body } \\
\text { length }\end{array}$ & Go-M (mm) & Measured from gonion point to mandibular midpoint \\
\hline 7. Sigmoid notch depth & $(\mathrm{mm})$ & $\begin{array}{l}\text { The distance along a perpendicular line from the deepest point of the sigmoid } \\
\text { notch to a line extending from condylion and coronoid process }\end{array}$ \\
\hline $\begin{array}{l}\text { 8. Posterior ramus notch } \\
\text { depth }\end{array}$ & $(\mathrm{mm})$ & $\begin{array}{l}\text { The distance along a perpendicular line from the deepest point of the ramus } \\
\text { notch concavity (Prnc) to a line connecting point Ar with the point of great- } \\
\text { est convexity on the posterior border of the angular process of the mandible } \\
\text { (PMC) }\end{array}$ \\
\hline $\begin{array}{l}\text { 9. Anterior ramus notch } \\
\text { depth }\end{array}$ & $(\mathrm{mm})$ & $\begin{array}{l}\text { The distance along a perpendicular line from the deepest point of the anterior } \\
\text { ramus notch concavity (Arnc) to Z-line (a line perpendicular to sigmoid notch } \\
\text { plane and tangent to descending anterior border of the ramus of mandible }\end{array}$ \\
\hline $\begin{array}{l}\text { 10. Antegonial notch } \\
\text { depth }\end{array}$ & $(\mathrm{mm})$ & $\begin{array}{l}\text { The distance along a perpendicular line from the deepest point of the mandib- } \\
\text { ular inferior border notch concavity (MNC) to mandibular plane }\end{array}$ \\
\hline 11. Retromolar space & $\mathrm{M} 2-\mathrm{Z}(\mathrm{mm})$ & $\begin{array}{l}\text { The distance between the distal contact point of the second molar and a line } \\
\text { perpendicular to Z plane. }\end{array}$ \\
\hline 12. Third Molar Width & $(\mathrm{mm})$ & The mesiodistal tooth width \\
\hline $\begin{array}{l}\text { Retromolar space } / 3 \mathrm{M} \\
\text { width }\end{array}$ & Ratio & Retromolar space divided by the Third molar width \\
\hline
\end{tabular}

Table 3 Angular measurements

\begin{tabular}{|l|l|l|}
\hline Measurement & Abbreviation & Description \\
\hline $\begin{array}{l}\text { 1. Angle between } \\
\text { condyle and Coronoid } \\
\text { process }\end{array}$ & Co-Cor $^{\circ}$ & $\begin{array}{l}\text { Formed by the intersection between the two lines drawn from Co } \\
\text { and Cor along their long axis }\end{array}$ \\
\hline 2. Gonial angle & Ar and PMC-IMCa and IMCb ${ }^{\circ}$ & $\begin{array}{l}\text { The angle formed by drawing two lines: the ramus plane (Ar and } \\
\text { PMC) and the mandibular plane (IMCa and IMCb) }\end{array}$ \\
\hline $\begin{array}{l}\text { 3. Inclination of lower } \\
\text { posterior teeth }\end{array}$ & L6-MP $^{\circ}$ & $\begin{array}{l}\text { The angle formed between the long axis of the first molar (drawn } \\
\text { through the midpoint of the occlusal surface and the midpoint of } \\
\text { the bifurcation) and the mandibular plane }\end{array}$ \\
\hline 4. Angle of Impaction & L8-MP $^{\circ}$ & $\begin{array}{l}\text { The angle formed between the long axis of the third molar (drawn } \\
\text { through the midpoint of the occlusal surface and the midpoint of } \\
\text { the bifurcation) and the mandibular plane }\end{array}$ \\
\hline
\end{tabular}

Hasan, ${ }^{19}$ who failed to find any significant difference between normal and impacted groups.

In this study, the control group showed significant wider ramal width than the impacted group $(p<0.001)$. This result is not in line with the results obtained by Hassan, ${ }^{19}$ who found significant wider ramal width in the impaction group. This difference may be a result of the different measurement technique used, sampling differences.

The results of the present study showed that the sigmoid notch depth was significantly deeper in the control group than in the impacted group $(p<0.001)$.This might be explained with reference to the following factors that may influence the sigmoid notch depth: ramus heights, condylar and coronoid process heights, and the angle between the condyle and coronoid processes, in which the control group showed significant longer ramus heights and significantly smaller angle between condyle and coronoid process than impacted group (this means less backward and forward slope of the anterior and posterior borders of the ramus in the control group). This hints that sigmoid notch depth is 
Table 4 Methodological tracing errors

\begin{tabular}{|l|l|l|l|l|}
\hline Variable & Reliability & Lower bond & Upper bond & $p$-Value \\
\hline Condyle length (mm) & $0.99^{* * *}$ & 0.98 & 0.99 & 0.000 \\
\hline Coronoid length (mm) & $0.99^{* * *}$ & 0.98 & 0.99 & 0.000 \\
\hline Ramus height (mm) & $0.91^{* * *}$ & 0.82 & 0.95 & 0.000 \\
\hline Total ramus height (mm) & $0.89^{* * *}$ & 0.78 & 0.94 & 0.000 \\
\hline Ramal width (mm) & $0.94^{* * *}$ & 0.89 & 0.97 & 0.000 \\
\hline Mandibular body length (mm) & $0.95^{* * *}$ & 0.91 & 0.97 & 0.000 \\
\hline Sigmoid notch depth (mm) & $0.97^{* * *}$ & 0.95 & 0.98 & 0.000 \\
\hline Posterior ramus notch depth (mm) & $0.99^{* * *}$ & 0.99 & 0.99 & 0.000 \\
\hline Anterior ramus notch depth (mm) & $0.99^{* * *}$ & 0.99 & 0.99 & 0.000 \\
\hline Antegonial notch depth (mm) & $0.99^{* * *}$ & 0.99 & 0.99 & 0.000 \\
\hline Third molar width (mm) & $0.99^{* * *}$ & 0.99 & 0.99 & 0.000 \\
\hline Retromolar space (mm) & $0.98^{* * *}$ & 0.97 & 0.99 & 0.000 \\
\hline $\begin{array}{l}\text { Angle between condyle and coronoid } \\
\text { process (deg) }\end{array}$ & $0.98^{* * *}$ & 0.97 & 0.99 & 0.96 \\
\hline Gonial angle (deg) & & $0.92^{* * *}$ & 0.84 & 0.98 \\
\hline Inclination of lower posterior teeth (deg) & $0.96^{* * *}$ & 0.93 & 0.98 & 0.000 \\
\hline Angle of Impaction (deg) & $0.99^{* * *}$ & & 0.000 \\
\hline
\end{tabular}

${ }^{* * *} p<0.001$

Table 5 Means and standard deviations of the mandibular dimensions between control and impacted groups

\begin{tabular}{|c|c|c|c|c|c|}
\hline \multirow[t]{2}{*}{ Variable } & \multicolumn{2}{|c|}{ Control group $(n=125)$} & \multicolumn{2}{|c|}{ Impacted group $(n=115)$} & \multirow[t]{2}{*}{$p$-Value } \\
\hline & Mean & SD & Mean & SD & \\
\hline Condyle length (mm) & 17.51 & 3.28 & 16.18 & 3.04 & 0.0000 \\
\hline Coronoid length (mm) & 13.16 & 3.20 & 12.50 & 3.06 & 0.03 \\
\hline Ramus height (mm) & 46.22 & 6.34 & 44.32 & 5.62 & 0.001 \\
\hline Total ramusheight (mm) & 58.20 & 6.88 & 54.47 & 6.44 & 0.000 \\
\hline Ramal width (mm) & 29.04 & 3.97 & 27.81 & 3.11 & 0.000 \\
\hline Mandibular body length (mm) & 88.52 & 9.35 & 87.54 & 7.56 & 0.23 \\
\hline Sigmoid notch depth (mm) & 13.87 & 2.46 & 12.93 & 2.18 & 0.000 \\
\hline Posterior ramus notch depth (mm) & 2.88 & 0.97 & 2.52 & 0.80 & 0.000 \\
\hline Anterior ramus notch depth (mm) & 3.40 & 2.06 & 2.78 & 1.57 & 0.001 \\
\hline Antegonial notch depth (mm) & 1.87 & 1.02 & 1.81 & 0.91 & 0.47 \\
\hline Third molar width (mm) & 11.04 & 0.93 & 10.93 & 0.96 & 0.23 \\
\hline Retromolar space (mm) & 10.72 & 3.61 & 8.21 & 3.48 & 0.000 \\
\hline Retromolar space/3M width ratio & 0.97 & 0.34 & 0.75 & 0.32 & 0.000 \\
\hline $\begin{array}{l}\text { Angle between condyle and coronoid } \\
\text { process (deg) }\end{array}$ & 39.68 & 8.74 & 41.21 & 9.35 & 0.07 \\
\hline Gonial angle (deg) & 122.81 & 10.68 & 125.47 & 8.24 & 0.004 \\
\hline Inclination of lower posterior teeth (deg) & 81.25 & 10.76 & 83.74 & 11.99 & 0.02 \\
\hline Angle of Impaction (deg) & 72.07 & 13.64 & 39.13 & 22.73 & 0.000 \\
\hline
\end{tabular}

Note: $n=$ number of subjects.

more likely to be more in-depth in the control group; however, the present findings stand alone, and further investigations are required before such conclusions are drawn.

According to the results of this study, the posterior and anterior ramus notch depths were significantly shallower in the impacted group than in the normal group $(p<0.001)$.
This finding might be due to the failure of remodeling and resorption of the anterior and posterior surfaces of the ramus, and more backward and forward slopes of the anterior and posterior borders of the ramus presented by the significant smaller angle between the condyle and coronoid process in the impacted group. 
Table 6 Correlation between retromolar space and mandibular measurements

\begin{tabular}{|c|c|c|c|c|c|c|c|c|}
\hline \multirow[t]{3}{*}{ Variable } & \multicolumn{4}{|c|}{ Control group } & \multicolumn{4}{|c|}{ Impacted group } \\
\hline & \multicolumn{4}{|c|}{ Retromolar space } & \multicolumn{4}{|c|}{ Retromolar space } \\
\hline & $r$ & $R^{2}$ & $R^{2(\mathrm{ADJ})}$ & $p$-Value & $r$ & $R^{2}$ & $R^{2(\mathrm{ADJ})}$ & $p$-Value \\
\hline Condyle length & 0.08 & 0.006 & 0.002 & 0.231 & 0.07 & 0.005 & 0.001 & 0.260 \\
\hline Coronoid length & 0.17 & 0.03 & 0.03 & 0.007 & 0.17 & 0.029 & 0.025 & 0.007 \\
\hline Ramal height I & 0.17 & 0.03 & 0.02 & 0.008 & 0.36 & 0.126 & 0.123 & 0.000 \\
\hline Ramal height II & 0.18 & 0.03 & 0.03 & 0.005 & 0.34 & 0.115 & 0.111 & 0.000 \\
\hline Ramal width & 0.04 & 0.00 & -0.003 & 0.567 & 0.15 & 0.022 & 0.018 & 0.020 \\
\hline Corpus length & 0.09 & 0.01 & 0.00 & 0.164 & 0.11 & 0.013 & 0.009 & 0.070 \\
\hline Sigmoid notch depth & 0.06 & 0.00 & 0.00 & 0.377 & 0.10 & 0.011 & 0.007 & 0.103 \\
\hline Posterior ramus notch depth & 0.30 & 0.09 & 0.09 & 0.000 & 0.18 & 0.033 & 0.03 & 0.004 \\
\hline Anterior ramus notch depth & 0.45 & 0.20 & 0.20 & 0.000 & 0.37 & 0.134 & 0.131 & 0.000 \\
\hline Antegonial notch depth & 0.00 & 0.00 & 0.00 & 0.979 & 0.05 & 0.002 & -0.002 & 0.468 \\
\hline Third molar width & 0.12 & 0.01 & 0.01 & 0.066 & 0.07 & 0.005 & 0.001 & 0.254 \\
\hline Gonial angle & 0.18 & 0.03 & 0.03 & 0.004 & 0.07 & 0.005 & 0.001 & 0.249 \\
\hline $\begin{array}{l}\text { Angle between condyle and } \\
\text { coronoid process }\end{array}$ & 0.01 & 0.00 & 0.00 & 0.862 & 0.07 & 0.005 & 0.001 & 0.277 \\
\hline $\begin{array}{l}\text { Inclination of lower posteri- } \\
\text { or teeth }\end{array}$ & 0.28 & 0.08 & 0.08 & 0.000 & 0.23 & 0.054 & 0.05 & 0.000 \\
\hline Angle of Impaction & 0.35 & 0.12 & 0.12 & 0.000 & 0.05 & 0.002 & -0.002 & 0.435 \\
\hline $\begin{array}{l}\text { Retromolar space } / 3 \mathrm{M} \text { width } \\
\text { ratio }\end{array}$ & 0.96 & 0.927 & 0.927 & 0.000 & 0.97 & 0.945 & 0.945 & 0.000 \\
\hline
\end{tabular}

Note: $r$ = Pearson correlation coefficient; $R^{2}=$ squared multiple correlation coefficient; $\left.R^{2(\mathrm{AD})}\right)=$ adjusted coefficient of determination, $p<0.05$.

When comparing mandibular body length (Go-mandibular midpoint, M) between groups, no statistically significant difference was found. This is consistent with previous studies of Dierkes ${ }^{20}$ and Kaplan ${ }^{21}$ but disagrees with the findings of Hassan, ${ }^{19}$ Broadbent, ${ }^{8}$ Björk, ${ }^{9}$ and Capelli ${ }^{18}$ who reported significant smaller mandibular length in the impacted third molars subjects.

The results of the present study showed that the mean retromolar space measured from a line tangent to descending anterior border of ramus to the distal surface of the second molar (M2-Z) was found to be $10.7 \pm 3.6 \mathrm{~mm}$ in the control group, and $8.2 \pm 3.4 \mathrm{~mm}$ in the impacted group. The retromolar space was significantly larger in the erupted group than in the impacted group $(p<0.001)$.

Uthman ${ }^{22}$ measured the retromolar space on panoramic radiographs, and concluded that this distance should be higher than $11 \mathrm{~mm}$ for females and $12 \mathrm{~mm}$ for males; this is within the range of the present investigation for men in the control group.

Our mean value of both groups ( $10.7 \pm 3.6 \mathrm{~mm}$ for control group and $8.2 \pm 3.4 \mathrm{~mm}$ for impacted group) was less than that reported by Hattab and Alhaija ${ }^{16}$ for Jordanians $(14.4 \pm 2.4 \mathrm{~mm}$ for erupted group and $11.06 \pm 2.6 \mathrm{~mm}$ for impacted group) and Qamruddin et $\mathrm{a}^{23}$ for Pakistanians $(16.3 \pm 2.5 \mathrm{~mm}$ for normal group and $11.2 \pm 3.6$ for impacted group).

On the other hand, Behbehani et $\mathrm{al}^{3}$ using lateral cephalograms suggested that the eruption space could be a good predictor for third molar eruption when measured to Ricketts' Xi point rather than to the anterior border of the ramus. They believed that it might be due to the large method error, and the complexity of locating the anterior border of the ramus on the lateral cephalograms, especially with double contours of the right and left sides in projection. In the present study, the eruption space was measured from the distal surface of the second molar to the anterior border of the ramus (M2-Z). Our finding is in line with the previous report that panoramic radiographs can offer better measurement due to the simplicity of locating the anterior border of the ramus and absence of double counters between the right and left sides and less method error. ${ }^{24}$

The average space/crown width ratio was 0.97 for the control group and 0.75 for the impacted group. This result is close to the value obtained by Hattab and Alhaija ${ }^{16}$ for Jordanian subjects, and that might be due to the similarity of the inclusion criteria and ethnic background. Previous reports ${ }^{16,25}$ indicated that when the ratio of retromolar space to third molar crown width is at least $1,69 \%$ of third molars erupt, a finding inconsistent with our present study.

Based on the results of the present study, there was a significant difference between groups about the gonial angle in which the control group showed smaller gonial angle than the impacted group. Our finding is in agreement with the results of previous studies. ${ }^{15,16}$

Some studies reported smaller and acuter gonial angle among impacted group compared with the normal group, ${ }^{25,26}$ which has not been detected in our sample in which the control group showed smaller gonial angle than the impacted 
group. Our finding disagrees with the results obtained by Behbehani et $\mathrm{al}^{3}$ who reported that small mandibular plane and gonial angles are associated with an increased risk for mandibular impaction.

Regarding the angulations of lower posterior teeth, the mandibular first molar inclinations were found to be in a more upright position in the impacted group compared with the control group $(p<0.05)$, resulting in less retromolar space that might lead to insufficient space required for the eruption of third molars in the impacted group. On the contrary, the third molar was more inclined in the impacted group than in the normal group $(p<0.001)$. It has been demonstrated that the higher the inclination of the posterior teeth, the greater is the probability of impaction. ${ }^{15,27,28,29,30}$ Our results support the findings of Ricketts, ${ }^{5}$ Capelli, ${ }^{18}$ Hassan, ${ }^{19}$ Shiller, ${ }^{28}$ Richardson, ${ }^{31}$ and Begg $^{32}$ in that the initial angulation of the lower third molar to the mandibular plane can be a factor in predicting impaction. Additionally, Uthman ${ }^{22}$ concluded that the third molar angle should be greater than $40^{\circ}$ as the angle decreases, the chances for impaction increases, which supports the results of the present study.

This study showed a significant but weak correlation between coronoid height, ramal height, and total ramal height with retromolar space required for the eruption of the third molar. These parameters could be a relevant indicator for predicting the eruption or impaction of third molars. The same tendency could be applied to the posterior ramus notch depth, anterior ramus notch depth, the inclination of lower posterior teeth, and retromolar space/3M width ratio, which showed a significant correlation with retromolar space.

The present study showed no correlation between the size of the gonial angle and the impaction of the third molars. It has been reported that a smaller and acuter gonial angle was more common among members of the impacted group, ${ }^{25,26}$ a tendency that has not been detected in our sample. Our finding is in agreement with the results of previous studies of Hattab and Alhaija, ${ }^{16}$ Hassan, ${ }^{19}$ Mollaoglu et al ${ }^{27}$ and disagrees with that of Behbehani et al. ${ }^{3}$ who reported that small mandibular plane and gonial angles are associated with an increased risk for mandibular impaction.

In spite of the limitation of this study of using two-dimensional radiographs, some obvious variations between groups included in this study are possibly helpful during prediction and treatment planning. However, further research using a contemporary approach such as cone beam computed tomography to elucidate the difference between groups is recommended.

\section{Conclusion}

The present study found that the configuration of the mandibular ramus appears to be discrete in many aspects in the erupted other than impacted lower third molar subjects, which might be a possible cause for the impaction.

\section{Conflict of Interest}

None declared.

\section{References}

1 Andreasen JO, In: epidemiology of third molar impaction. Andreasen, JO, Peterson, JK, Laskin, DM, eds. Textbook and Color Atlas of Tooth Impactions. Copenhagen: Munksgaard;1997;222-223

2 Bishara SE. Third molars: a dilemma! Or is it? Am J Orthod Dentofacial Orthop 1999;115(6):628-633

3 Behbehani F, Artun J, Thalib L. Prediction of mandibular third-molar impaction in adolescent orthodontic patients. Am J Orthod Dentofacial Orthop 2006;130(1):47-55

4 Bjork A, Jensen E, Palling M. Mandibular growth and third molar impaction. Acta Odontol Scand 1956;14:231-272

5 Ricketts RM. A principle of arcial growth of the mandible. Angle Orthod 1972;42(4):368-386

6 Schulhof RJ. Third molars and orthodontic diagnosis. J Clin Orthod 1976;10(4):272-281

7 Forsberg CM, Vingren B, Wesslén U. Mandibular third molar eruption in relation to available space as assessed on lateral cephalograms. Swed Dent J 1989;13(1-2):23-31

8 Broadbent $B$. The influence of the third molars on the alignment of teeth. Am J Orthod 1943;29:312-330

9 Bjork A. Variations in the growth pattern of the human mandible: longitudinal radiographic study by the implant method. J Dent Res 1963;42(1):400-411

10 Alrahabi M, Zafar M. Anatomical variations of mental foramen: a retrospective cross-sectional study. Int J Morphol 2018;36(3):1124-1129

11 Al-Zoubi H, Alharbi AA, Ferguson DJ. Zafar MS. Frequency of impacted teeth and categorization of impacted canines: a retrospective radiographic study using orthopantomograms. Eur J Dent 2017;11(1):117-121

12 Gupta S, Jain S. Orthopantomographic analysis for assessment of mandibular asymmetry. J Indian Orthod Soc 2012;46:33-37

13 Ongkosuwito EM, Dieleman MM, Kuijpers-Jagtman AM, Mulder PG, van Neck JW. Linear mandibular measurements: comparison between orthopantomograms and lateral cephalograms. Cleft Palate Craniofac J 2009;46(2):147-153

14 Haralabakis H. Observations on the time of eruption, congenital absence and impaction of the third molar teeth. Trans Eur Orthod Soc 1957;33:308-309

15 Hattab FN. Positional changes and eruption of impacted mandibular third molars in young adults. A radiographic 4-year follow-up study. Oral Surg Oral Med Oral Pathol Oral Radiol Endod 1997;84(6):604-608

16 Hattab FN, Alhaija ES. Radiographic evaluation of mandibular third molar eruption space. Oral Surg Oral Med Oral Pathol Oral Radiol Endod 1999;88(3):285-291

17 Scherstén E, Lysell L, Rohlin M. Prevalence of impacted third molars in dental students. Swed Dent J 1989;13(1-2):7-13

18 Capelli J, Jr. Mandibular growth and third molar impaction in extraction cases. Angle Orthod 1991;61(3):223-229

19 Hassan AH. Mandibular cephalometric characteristics of a Saudi sample of patients having impacted third molars. Saudi Dent J 2011;23(2):73-80

20 Dierkes DD. An investigation of the mandibular third molars in orthodontic cases. Angle Orthod 1975;45(3):207-212

21 Kaplan RG. Some factors related to mandibular third molar impaction. Angle Orthod 1975;45(3):153-158

22 Uthman AT. Retromolar space analysis in relation to selected linear and angular measurements for an Iraqi sample. Oral Surg Oral Med Oral Pathol Oral Radiol Endod 2007;104(4):e76-e82

23 Qamruddin I, Qayyum W, Haider SM, Siddiqui SW, Rehan F. Differences in various measurements on panoramic radiograph among erupted and impacted lower third molar groups. J Pak Med Assoc 2012;62(9):883-887 
24 Indira AP, Markande A, David MP. Mandibular ramus: an indicator for sex determination - a digital radiographic study. J Forensic Dent Sci 2012;4(2):58-62

25 Ganss C, Hochban W, Kielbassa AM, Umstadt HE. Prognosis of third molar eruption. Oral Surg Oral Med Oral Pathol 1993;76(6):688-693

26 Richardson ME. The etiology and prediction of mandibular third molar impaction. Angle Orthod 1977;47(3):165-172

27 Mollaoglu N, Çetiner S, Güngör K. Patterns of third molar impaction in a group of volunteers in Turkey. Clin Oral Investig 2002;6(2):109-113

28 Shiller WR. Positional changes in mesio-angular impacted mandibular third molars during a year. J Am Dent Assoc 1979;99(3):460-464
29 Garcia RI, Chauncey HH. The eruption of third molars in adults: a 10-year longitudinal study. Oral Surg Oral Med Oral Pathol 1989;68(1):9-13

30 Ventä I, Murtomaa H, Turtola L, Meurman J, Ylipaavalniemi P. Clinical follow-up study of third molar eruption from ages 20 to 26 years. Oral Surg Oral Med Oral Pathol 1991;72(2):150-153

31 Richardson $M$. Changes in lower third molar position in the young adult. Am J Orthod Dentofacial Orthop 1992;102(4):320-327

32 Begg PR. Stone Age man's dentition. Am J Orthod 1954;40:298-312 